\title{
Editorial: Physiological Aspects of Non-proteinogenic Amino Acids in Plants
}

\author{
Georg Jander ${ }^{1 *}$, Uener Kolukisaoglu ${ }^{2}$, Mark Stahl ${ }^{2}$ and Gyeong Mee Yoon ${ }^{3}$ \\ ${ }^{1}$ Boyce Thompson Institute, Ithaca, NY, United States, ${ }^{2}$ Center for Plant Molecular Biology, University of Tuebingen, \\ Tuebingen, Germany, ${ }^{3}$ Department of Botany and Plant Pathology, Center for Plant Biology, Purdue University, West \\ Lafayette, IN, United States
}

Keywords: non-proteinogenic, amino acid, metabolism, biosynthesis, plant

\section{Editorial on the Research Topic}

\section{Physiological Aspects of Non-proteinogenic Amino Acids in Plants}

In addition to the canonical 20 amino acids that constitute the essential building blocks of proteins, plants produce a wide variety of non-proteinogenic amino acids (NPAAs; Fowden, 1981, Rosenthal, 1982, Barrett, 1985, Bell, 2003). Some of these plant metabolites are components of central metabolism, serving as intermediates in biosynthetic pathways or as signaling molecules during plant stress responses. NPAAs such as ornithine, citrulline, arginosuccinate, homoserine, homocysteine, and cystathionine, are well-studied metabolic intermediates and are likely to be present in all plant species. Other commonly encountered plant NPAAs, for instance pipecolic

OPEN ACCESS

Edited by:

Adriano Nunes-Nesi,

Universidade Federal de Viçosa, Brazil

Reviewed by:

Petronia Carillo,

University of Campania Luigi

Vanvitelli, Italy

*Correspondence:

Georg Jander

gj32@cornell.edu

Specialty section: This article was submitted to Plant Physiology,

a section of the journal

Frontiers in Plant Science

Received: 12 December 2019 Accepted: 27 November 2020

Published: 17 December 2020

Citation:

Jander G, Kolukisaoglu U, Stahl M and Yoon GM (2020) Editorial:

Physiological Aspects of

Non-proteinogenic Amino Acids in

Plants. Front. Plant Sci. 11:519464.

doi: 10.3389/fp/s.2020.519464 acid with its derivatives, can function as signaling molecules that influence plant development, physiology, and defense responses (Huang et al., 2020).

A particularly noteworthy NPAA, $\gamma$-aminobutyric acid (GABA), is essential for many physiological and developmental processes in plants, including energy dissipation, maintenance of carbon/nitrogen balance, pollen tube growth, and fruit development (Kinnersley and Turano, 2000, Palanivelu et al., 2003, Fait et al., 2008, Snowden et al., 2015, Amir et al., 2018). Functioning as both signaling molecule and a regulator of plant metabolism, GABA can modulate plant immune responses (Kim et al., 2013, Wang et al., 2019, Deng et al., 2020, Tarkowski et al., 2020). Numerous studies have shown a role for GABA accumulation in protecting plants against abiotic stresses such as drought and salinity (Bor et al., 2009, Akcay et al., 2012, Vijayakumari and Puthur, 2015, Mekonnen, 2017, Carillo, 2018, Rezaei-Chiyaneh et al., 2018, Jin et al., 2019, Podlesakova et al., 2019).

NPAAs that are not part of primary metabolism are often defense-related, providing protection against pests and pathogens, and typically have a more sporadic distribution in the plant kingdom (Bell, 1976). For instance, many legumes accumulate large amounts of canavanine or other NPAAs that not only function as defensive metabolites but also serve for nitrogen storage in the seeds (Huang et al., 2011). Canavanine is a structural analog of arginine and exerts its toxicity in animals by interfering with arginine-related metabolism, including nitric oxide synthase and incorporation of arginine into proteins (Bence and Crooks, 2003). In new research on the toxicity of canavanine in plants, Staszek et al. show that the canavanine-mediated inhibition of nitric oxide biosynthesis leads to formation of differentially nitrated proteins and a disruption of the antioxidant system in tomato roots.

Another NPAA, 1-aminocyclopropane carboxylate (ACC), is the direct precursor of ethylene, a gaseous hormone regulating a wide ranges of developmental and stress-related processes in plants (e.g., Lee et al., 2019, Seo and Yoon, 2019). However, as discussed by Polko and Kieber, ACC itself also functions as a plant signaling molecule. Physiological processes in plants that are 
influenced directly by ACC include stomatal development, cell wall biosynthesis, stress responses, and pathogen interactions (Xu et al., 2008, Tsuchisaka et al., 2009, Tsang et al., 2011, Yin et al., 2019). The levels of ACC in plants are critical for ethylene production and seem to be influenced by another group of NPAAs, the D-Amino acids. D-Amino acid isomers of the proteinogenic $L$-amino acids are produced by soil microbes and are taken up by plant roots, but can also be produced by plants themselves (Genchi, 2017). Although some $D$-amino acids are toxic to Arabidopsis thaliana (Arabidopsis) at low concentrations (Erikson et al., 2004), the metabolism of $D$-amino acids strongly varies between different Arabidopsis ecotypes (Gordes et al., 2013). Suarez et al. used natural accessions and transgenic mutant lines to identify and investigate AtDAT1, a major $D$-amino acid transaminase in Arabidopsis. Decreased activity of this enzyme leads to enhanced susceptibility to $D$-methionine and increased $D$-amino acid abundance stimulated accumulation of ethylene. In this study it was demonstrated, that the regulation of $D$-methionine and ACC derivatives in plants are interlinked. However, the detailed mechanisms by which $D$-amino acids induce ethylene production remain to be investigated.

$\beta$-Amino acids, which have the amino group attached to the $\beta$ carbon rather than the adjacent $\alpha$-carbon, have been reported in many plant species (Kudo et al., 2014). Whereas, some $\beta$-amino acids, for instance $\beta$-tyrosine, have likely defensive functions in plants (Yan et al., 2015), others are essential components of primary metabolism. Parthasarathy et al. review the biosynthesis and function of $\beta$-alanine, which is not only a component of vitamin $\mathrm{B}_{5}$ and thereby is essential for Coenzyme A function,

\section{REFERENCES}

Akcay, N., Bor, M., Karabudak, T., Ozdemir, F., and Turkan, I. (2012). Contribution of Gamma amino butyric acid (GABA) to salt stress responses of Nicotiana sylvestris CMSII mutant and wild type plants. J. Plant Physiol. 169, 452-458. doi: 10.1016/j.jplph.2011.11.006

Amir, R., Galili, G., and Cohen, H. (2018). The metabolic roles of free amino acids during seed development. Plant Sci. 275, 11-18. doi: $10.1016 /$ j.plantsci.2018.06.011

Barrett, G. C. (1985). Chemistry and Biochemistry of the Amino Acids. London; NY: Chapman and Hall.

Bell, E. A. (1976). Uncommon amino acids in plants. FEBS Lett. 64, 29-35. doi: 10.1016/0014-5793(76)80241-4

Bell, E. A. (2003). Nonprotein amino acids of plants: significance in medicine, nutrition, and agriculture. J. Agric Food Chem. 51, 2854-2865. doi: $10.1021 /$ jf020880w

Bence, A. K., and Crooks, P. A. (2003). The mechanism of Lcanavanine cytotoxicity: arginyl tRNA synthetase as a novel target for anticancer drug discovery. J. Enzyme Inhib. Med. Chem. 18, 383-394. doi: 10.1080/1475636031000152277

Bor, M., Seckin, B., Ozgur, R., Yilmaz, O., Ozdemir, F., and Turkan, I. (2009). Comparative effects of drought, salt, heavy metal and heat stresses on gammaaminobutryric acid levels of sesame (Sesamum indicum L.). Acta Phys. Plant. 31, 655-659. doi: 10.1007/s11738-008-0255-2

Carillo, P. (2018). GABA shunt in durum wheat. Front. Plant Sci. 9:100. doi: 10.3389/fpls.2018.00100

Deng, X., Xu, X., Liu, Y., Zhang, Y., Yang, L., Zhang, S., et al. (2020). Induction of gamma-aminobutyric acid plays a positive role to Arabidopsis resistance against Pseudomonas syringae. J. Integr. Plant Biol. 62, 1797-1812. doi: $10.1111 /$ jipb. 12974 but also contributes to plant responses to both biotic and abiotic stresses. Although the $\beta$-alanine biosynthetic pathways are not yet completely elucidated in plants, spermine, spermidine, propionate, and uracil are known metabolic precursors.

The biosynthetic pathways of proteinogenic amino acids, and by extension the biosynthesis of NPAAs that serve as intermediates in these pathways, have been elucidated in Arabidopsis and other plant species (Jander and Joshi, 2010). However, the biosynthetic pathways and/or metabolic functions have been unraveled for only a few of the hundreds of other plant NPAAs, including $D$-amino acids, $\beta$-amino acids, other isomers, and structural mimics. Thus, there are many opportunities for novel discoveries in this research area. In particular, with the development of new research methods for studying non-model plant species at the molecular level, it will be possible to study the biosynthesis pathways, as well as structural, defensive, and signaling functions, of NPAAs that are not present in Arabidopsis.

\section{AUTHOR CONTRIBUTIONS}

GJ wrote the first draft. All authors contributed revisions and approved the published version of the manuscript.

\section{FUNDING}

This work was supported by and award from the Triad Foundation to GJ and US National Science Foundation award MCB-1817286 to GY.

Erikson, O., Hertzberg, M., and Nasholm, T. (2004). A conditional marker gene allowing both positive and negative selection in plants. Nat. Biotechnol. 22, 455-458. doi: 10.1038/nbt946

Fait, A., Fromm, H., Walter, D., Galili, G., and Fernie, A. R. (2008). Highway or byway: the metabolic role of the GABA shunt in plants. Trends Plant Sci. 13, 14-19. doi: 10.1016/j.tplants.2007.10.005

Fowden, L. (1981). Non-protein amino acids of plants. Food Chem. 6, 201-211. doi: 10.1016/0308-8146(81)90009-1

Genchi (2017). An overview on D-amino acids. Amino Acids. 49, 1521-1533. doi: 10.1007/s00726-017-2459-5

Gordes, D., Koch, G., Thurow, K., and Kolukisaoglu, U. (2013). Analyses of Arabidopsis ecotypes reveal metabolic diversity to convert D-amino acids. Springerplus. 2:559. doi: 10.1186/2193-1801$2-559$

Huang, T., Jander, G., and De Vos, M. (2011). Non-protein amino acids in plant defense against insect herbivores: representative cases and opportunities for further functional analysis. Phytochemistry 72, 1531-1537. doi: 10.1016/j.phytochem.2011.03.019

Huang, W., Wang, Y., Li, X., and Zhang, Y. (2020). Biosynthesis and regulation of salicylic acid and $\mathrm{N}$-hydroxypipecolic acid in plant immunity. Mol Plant. 13, 31-41. doi: 10.1016/j.molp.2019.12.008

Jander, G., and Joshi, V. (2010). Recent progress in deciphering the biosynthesis of aspartate-derived amino acids in plants. Mol Plant. 3, 54-65. doi: $10.1093 / \mathrm{mp} / \mathrm{ssp} 104$

Jin, X., Liu, T., Xu, J., Gao, Z., and Hu, X. (2019). Exogenous GABA enhances muskmelon tolerance to salinity-alkalinity stress by regulating redox balance and chlorophyll biosynthesis. BMC Plant Biol. 19:48. doi: 10.1186/s12870-019-1660-y

Kim, N. H., Kim, B. S., and Hwang, B. K. (2013). Pepper arginine decarboxylase is required for polyamine and gamma-aminobutyric acid 
signaling in cell death and defense response. Plant Physiol. 162, 2067-2083. doi: $10.1104 /$ pp.113.217372

Kinnersley, A. M., and Turano, F. J. (2000). Gamma aminobutyric acid (GABA) and plant responses to stress. Crit. Rev. Plant Sci. 19, 479-509.

Kudo, F., Miyanaga, A., and Eguchi, T. (2014). Biosynthesis of natural products containing beta-amino acids. Nat Prod Rep. 31, 1056-1073. doi: $10.1039 / \mathrm{c} 4 \mathrm{np} 00007 \mathrm{~b}$

Lee, H. Y., Chen, Z., Zhang, C., and Yoon, G. M. (2019). Editing of the OsACS locus alters phosphate deficiency-induced adaptive responses in rice seedlings. J. Exp. Bot. 70, 1927-1940. doi: 10.1093/jxb/erz074

Mekonnen, D. W. (2017). Oversensitivity of Arabidopsis gad1/2 mutant to $\mathrm{NaCl}$ treatment reveals the importance of GABA in salt stress responses. African J. Plant Sci. 11, 252-263. doi: 10.5897/AJPS2017.1551

Palanivelu, R., Brass, L., Edlund, A. F., and Preuss, D. (2003). Pollen tube growth and guidance is regulated by $P O P 2$, an Arabidopsis gene that controls GABA levels. Cell 114, 47-59. doi: 10.1016/s0092-8674(03)00479-3

Podlesakova, K., Ugena, L., Spichal, L., Dolezal, K., and De Diego, N. (2019). Phytohormones and polyamines regulate plant stress responses by altering GABA pathway. N. Biotechnol. 48, 53-65. doi: 10.1016/j.nbt.2018.07.003

Rezaei-Chiyaneh, E., Seyyedi, S. M., Ebrahimian, E., Moghaddam, S. S., and Damalas, C. A. (2018). Exogenous application of gamma-aminobutyric acid (GABA) alleviates the effect of water deficit stress in black cumin (Nigella sativa L.). Ind. Crop. Prod. 112, 741-748. doi: 10.1016/j.indcrop.2017.12.067

Rosenthal, G. A. (1982). Plant Nonprotein Amino and Imino Acids: Biological, Biochemical, and Toxicological Properties. New York, N.Y.: Academic Press.

Seo, D. H., and Yoon, G. M. (2019). Light-induced stabilization of ACS contributes to hypocotyl elongation during the dark-to-light transition in Arabidopsis seedlings. Plant J. 98, 898-911. doi: 10.1111/tpj.14289

Snowden, C. J., Thomas, B., Baxter, C. J., Smith, J. A., and Sweetlove, L. J. (2015). A tonoplast Glu/Asp/GABA exchanger that affects tomato fruit amino acid composition. Plant J. 81, 651-660. doi: 10.1111/tpj.12766

Tarkowski, L. P., Signorelli, S., and Höfte, M. (2020). gamma-Aminobutyric acid and related amino acids in plant immune responses: Emerging mechanisms of action. Plant Cell Environ. 43, 1103-1116. doi: 10.1111/pce.13734

Tsang, D. L., Edmond, C., Harrington, J. L., and Nuhse, T. S. (2011). Cell wall integrity controls root elongation via a general 1-aminocyclopropane-1carboxylic acid-dependent, ethylene-independent pathway. Plant Physiol. 156, 596-604. doi: 10.1104/pp.111.175372
Tsuchisaka, A., Yu, G., Jin, H., Alonso, J. M., Ecker, J. R., Zhang, X., et al. (2009). A combinatorial interplay among the 1-aminocyclopropane1-carboxylate isoforms regulates ethylene biosynthesis in Arabidopsis thaliana. Genetics 183, 979-1003. doi: 10.1534/genetics.109.1 07102

Vijayakumari, K., and Puthur, J. T. (2015). Gamma-aminobutyric acid (GABA) priming enhances the osmotic stress tolerance in Piper nigrum Linn. plants subjected to PEG-induced stress. Plant Growth Reg. 78, 57-67. doi: 10.1007/s10725-0150074-6

Wang, G., Kong, J., Cui, D., Zhao, H., Niu, Y., Xu, M., et al. (2019). Resistance against Ralstonia solanacearum in tomato depends on the methionine cycle and the gamma-aminobutyric acid metabolic pathway. Plant J. 97, 1032-1047. doi: 10.1111/tpj.14175

Xu, S. L., Rahman, A., Baskin, T. I., and Kieber, J. J. (2008). Two leucine-rich repeat receptor kinases mediate signaling, linking cell wall biosynthesis and ACC synthase in Arabidopsis. Plant Cell. 20, 3065-3079. doi: 10.1105/tpc.108.0 63354

Yan, J., Aboshi, T., Teraishi, M., Strickler, S. R., Spindel, J. E., Tung, C. W., et al. (2015). The rice tyrosine aminomutase TAM1 is required for beta-tyrosine biosynthesis. Plant Cell. 27, 1265-1278. doi: 10.1105/tpc.15. 00058

Yin, J., Zhang, X., Zhang, G., Wen, Y., Liang, G., and Chen, X. (2019). Aminocyclopropane-1-carboxylic acid is a key regulator of guard mother cell terminal division in Arabidopsis thaliana. J. Exp. Bot. 70, 897-908. doi: $10.1093 /$ jxb/ery413

Conflict of Interest: The authors declare that the research was conducted in the absence of any commercial or financial relationships that could be construed as a potential conflict of interest.

Copyright (c) 2020 Jander, Kolukisaoglu, Stahl and Yoon. This is an open-access article distributed under the terms of the Creative Commons Attribution License (CC $B Y)$. The use, distribution or reproduction in other forums is permitted, provided the original author(s) and the copyright owner(s) are credited and that the original publication in this journal is cited, in accordance with accepted academic practice. No use, distribution or reproduction is permitted which does not comply with these terms. 